\title{
Analysis of patent sources in the field of environmental monitoring of objects
}

\author{
Alexandra Petryaeva ${ }^{1}$, Marina Bolsunovskaya $^{1}$, Svetlana Shirokova ${ }^{1 *}$, Aleksandr \\ Leksashov, Andrey Zhukov ${ }^{1}$, Aleksander Kuptsov ${ }^{1}$, and Dmitry Kazakov ${ }^{1}$ \\ ${ }^{1}$ Peter the Great St. Petersburg Polytechnic University, Polytechnicheskaya, 29, 195251, Saint- \\ Petersburg, Russian Federation
}

\begin{abstract}
In the modern world, trends are constantly changing, and the process of globalization sets many new directions for development. This undoubtedly affects the approaches to each individual problem, among which the issue of maintaining the balance of the environment and technological progress is acutely raised. New risks and threats accompany the need for humanity to develop comprehensive solutions to solve critical situations that can later be predicted and acted on ahead of the curve. This article examines the concept of "environmental monitoring" in the modern context: the adaptation of systems to the process of globalization, as well as the consideration of a number of patents on the selected topic.
\end{abstract}

\section{Introduction}

The problem of environmental conservation plays a global role in the life of modern man. Environmental protection is a versatile and multi-faceted process that requires efforts not only from one person but also from a number of countries and humanity as a whole. In a variety of types of both practical and scientific activities, the method of observing an object is used in order to study it for a long time and purposefully, to draw certain conclusions based on how the object works and behaves in its natural conditions. Experiencing the devastating effects of tornadoes, floods, earthquakes, and other environmental disasters, people have long, without even knowing it, implemented monitoring elements, accumulating experience, and predicting the consequences [1].

This article examines the concept of "environmental monitoring" in the historical context - the emergence of hydro monitoring technology, as well as the consideration of some existing patents in the selected field.

The purpose of this article is a comprehensive author's study of the problem of environmental conservation. This study is aimed at reviewing and analyzing patents in the field of environmental hydro monitoring by analyzing specific patent sources.

\footnotetext{
* Corresponding author: swchirokov@mail.ru
} 


\section{Materials and methods}

In the course of the study, an analysis of domestic patents in the field of environmental conservation monitoring was carried out, and a specific federal project, partially under the leadership of SPbPU, was considered - "Digital Ob-Irtysh Basin" [2]. The patent search was conducted according to certain criteria: keywords and time frame on the website of the Federal Institute of Industrial Property (FIPS) [3]. Currently, patenting is the most common and effective form of protection of the exclusive rights of the inventor to use the product of intellectual activity. At the same time, patent practice is a valuable material for analyzing the level and trends of innovative development in a particular area of environmental activity, and information about it can be used as an effective tool-assistant for enterprises that plan to switch to a systematic and integrated approach to studying the problem of monitoring.

According to the results of the search, 1,792 patents were found, of which 3 were selected for analysis. The study found that all patents have a clear focus - all of them are aimed at partial or full implementation of monitoring of water storage facilities in order to minimize the risks associated with both the internal environmental situation, biodiversity, and chemical emissions, but also with damage to the coastline and the general state of the basin in the context of technological discrete monitoring (individual stations or sensors that are not systematized and have separate data streams transmitted at the end of the previous processing stage - there is no complexity in the observations, and there is also a risk of data loss).

The following patent sources were analyzed as part of the study:

- Patent RU 2680652, the authors of which are Lepekhin P. P., Murasheva A. A., Shapovalov D. A., Vershinin V. V., and Rodionova O. M. This patent proposes the invention of integrated monitoring of the natural environment-monitoring a number of indicators (soil, atmosphere, water, subsurface, and so on). The development allows for comprehensive monitoring and analysis of metrics by combining flows in a single Center for Integrated Environmental Monitoring (CCMP) [4].

- Patent RU 105497, the patent holder of which is the Limited Liability Company "New Technologies" of Tula State University. The authors propose a device for environmental monitoring and display of atmospheric air pollution [5].

- Patent RU 90238, the authors of which are Panfilov A.V., Anaid Saini, Ludogovskaya T. A., which reveals the concept of"information system for monitoring the environmental situation". The system itself consists of mobile and stationary objects, an information processing center, a data storage server, and an individual navigation unit is located in each of the mobile and stationary objects [6].

The results of the analysis confirmed a high level of penetration of links in various technical areas, which will undoubtedly allow us to reflect the presence of environmental problems through a hydro monitoring system not only in one region but also around the world. This will contribute to more intensive observation and study of environmental problems in the most remote corners of the planet.

The task of protecting intellectual property requires the utmost care, precision, and cooperation at all levels of government. During this period of time, patenting is the most complete and widespread form of protection of the exclusive rights of the inventor to his product, as well as the possible use of the product of intellectual activity in general. The patent practice has a comprehensive approach and becomes a good tool for analyzing trends in innovative development.

For 2021, in the field of environmental monitoring, 1,792 patents were registered on the website of the Federal Institute of Industrial Property (FIPS), which cover not only partial monitoring of the water surface but also, for example, the introduction of entire monitoring 
systems, including not only hydro monitoring posts but also a whole network of sensors that, when working well, give a very accurate result for environmental analysis and forecasting.

The problem of preserving the environment and a careful attitude to biological diversity is on the main agenda of the world's population as a whole. Environmental monitoring has a comprehensive approach, as it includes a whole system of observations of the state of the environment: this can be a service of prompt warning about the detection of the discharge of polluted water by industrial enterprises into water sources and on the landscape; a service of prompt warning about exceeding the maximum permissible concentration of pollutants on a certain section of the river; so is the calculation of whole digital models of changes in hydrological parameters and the concentration of pollutants in different sections of the river [7].

The process of environmental monitoring has its origins in the first century AD: in the works of Gaius Secundus Pliny the Elder, a number of examples of the organization of observations of the natural environment were reflected. As many as thirty-seven volumes, which contained information not only about geography and botany but also about a whole range of sciences - such as astronomy, zoology, history. These scientific works became the most complete encyclopedia of knowledge before the Middle Ages. In the XX century, the term "monitoring" appeared in science to define a system of repeated targeted observations of one or more elements of the natural environment in real-time and space.

The objectives of monitoring are not only the prognostic component but also the development of various strategies for optimal management decisions to prevent the negative consequences of human activity in a particular reservoir [8].

For example, in the patent RU 2680652, the authors of which are Lepekhin P. P., Murasheva A. A., Shapovalov D. A., Vershinin V. V., and Rodionova O. M., the invention of integrated monitoring of the natural environment is proposed (monitoring a number of indicators for the atmosphere, water quality, soil condition, state and diversity of bioresources in order not only to extract the necessary information about the object of research but also to be able to early detect and establish a specific location of deviations from the established parameters). In contrast to the existing range of systems, this prototype offers a new technological solution that would be aimed at automation and autonomy of the integrated hydro monitoring system. That is, the main goal, which was guided by the authors of the invention, is to create not just individual observation stations, but not to be limited, to make a whole complex of monitoring the current situation. The objective of the invention is to be able to evaluate the results of the system comprehensively, weighing all the indicators from the particular to the general. The invention of the Federal State Budgetary Educational Institution of Higher Education "State University for Land Management" (patent holder) is intended for monitoring, monitoring, and analyzing the state of the natural environment of objects that are located on land, underwater, above water, as well as on water surfaces by combining information flows in a single Center for Integrated Monitoring of the Natural Environment (CCMPS) [9], functioning on the basis of the use of modern remote sensing methods using geoportals and metadata portals.

The patent RU 90238, the authors of which are Panfilov A.V., Anaid Saini, Ludogovskaya T. A., reveals the concept of an "information system for monitoring the environmental situation". The system itself consists of mobile and stationary objects, an information processing center, a data storage server, and an individual navigation unit is located in each of the mobile and stationary objects. The disadvantage of this technical solution is the relatively narrow functionality since the system allows you to switch and display information flows on the screen of a personal computer, but does not allow you to monitor the environment and notify about local environmental violations. 
Patent RU 105497, the patent holder of which is the Limited Liability Company "New Technologies" of Tula State University, offers a device for environmental monitoring and display of atmospheric air pollution [10]. This device contains sensors for remote environmental monitoring, a data collection and comparison center, an environmental control module equipped with gas sensors for environmental monitoring of the state of the atmosphere, recording devices connected to the data collection and comparison center, characterized in that additional sensors for environmental monitoring of the state of the atmosphere are introduced, a software and computing unit for predicting atmospheric pollution, a unit for building maps of atmospheric pollution fields. The device belongs to the environmental systems for collecting information, diagnosing the state of the atmosphere of an industrial region and is intended for use in the system of atmospheric protection measures for the rapid identification of sources of atmospheric pollution with the current regulatory and unauthorized level of emissions of harmful substances [11].

Within the framework of the work considered in the diploma project, a specific solution for the Ob-Irtysh basin is proposed. In the spring of 2020, the development of a new federal project "Digital Ob-Irtysh Basin" began in Kuzbass, which has already been supported by 8 regions of Russia, a wide range of experts, and the scientific community.

The project is of the highest relevance for many regions and for the whole country. The steady deterioration of the rivers of Siberia and the Urals exacerbates the issues of drinking water quality [12], the navigability of rivers, and the safety of hydraulic structures. Managers of all regions need working tools to manage the negative factors that have a critical impact on these processes, and now there is often not even reliable timely information for making managerial decisions.

The current state of affairs is limited to periodic monitoring of the values of individual indicators and reconciliation with established standards (maximum permissible concentration).

\section{Results}

To move from a system of discrete monitoring of individual indicators to the creation of a comprehensive management system for the entire range of river basin resources is what the project aims to achieve. To do this, it will be necessary to accurately determine the composition of critical factors, a set of specific indicators, and set their threshold values [13]. This will allow us to review the approaches to the organization of economic activities in the basin and move to the implementation of systematic measures to reduce the accumulated environmental damage.

Main implementation goals for the monitoring system:

- periodic monitoring of the values of individual indicators and reconciliation with established standards - atmospheric characteristics, soil condition, chemical composition, and biodiversity of the basin as a whole [14];

- continuous online monitoring of a set of indicators that characterize the state of the ecosystem of the water body and the entire river basin as a whole;

- modernization of the network of hydro monitoring posts, changing the system of the location of posts, equipped with modern digital equipment, changing the methods of data collection.

Building a management system based on big data and modern mathematical modeling technologies will allow us to move to effective measures to improve the health of the main rivers of Siberia and the Urals, and then scale this approach to other water bodies in Russia and other countries.

Modern technologies of mathematical modeling will allow the creation of effective tools of water resources management, and in the future to change the principles of 
regulatory impact, taking into account the most effective ways of risk prevention, conservation, and rational use of the entire complex of water resources in the territory of the Priobsky regions [15].

Data analysis and regulatory impact include:

- reconciliation with the established standards (maximum permissible concentration), established without taking into account the characteristics and condition of a particular water body and the type of man-made load on the water body;

- calculation of fees for environmental damage compensation and penalties for exceeding the maximum permissible concentration;

- creation of digital information models of a water body (with different functionality);

- development of methodology and creation of a digital double of the river basin as a techno-natural object;

- determination of the composition of critical indicators and their limit values based on modern technologies of mathematical modeling and big data processing.

- transition to regional maximum permissible concentrations, taking into account factors specific to a particular water body.

The development of a digital ecosystem of water resources management, with the creation of a whole list of functional services and super-services, will allow for the digital transformation of the water resources management system, and this project provides for a serious block of work in the field of regulatory regulation.

Water object - the object of monitoring. Management is reduced to identifying violations and deviations from the established standards [16].

\section{Discussion}

A water body is a complex of resources. The management system involves targeted planning and implementation of measures for the conservation and effective use of water resources, including measures to reduce accumulated environmental damage. It is based on a risk-based approach and operates with a specific set of indicators that are critical for water resources management [17].

The most important effect that can be obtained from the project is to increase the efficiency of public administration. Those areas that are currently problematic, sometimes poorly predictable, should become the object of system management. These are the state of ecosystems and improving the quality of drinking water, ensuring the preservation of navigability of rivers, the safety of hydraulic structures, and managing the life cycle of major capital construction projects, including the Arctic infrastructure. This is a set of issues that have a critical impact on the socio-economic development of the 14 Priobsky regions.

After the introduction of the new hydro monitoring system, a whole range of indicators will be observed at once [18].

The implementation consists in:

- modernization of the hydro monitoring system - switching to online mode;

- formation of Big Data, including collection, verification, and systematization of data for previous periods;

- development of big data processing methodology and creation of digital models of the river basin as a techno-nature object;

- formation of a matrix of critical parameters and resource constraints;

- creating a "digital double" of a river basin with a high degree of adequacy [19];

- creating a digital river basin ecosystem with functional services and super services;

- integration into the national data management system; 
- making systemic changes to the regulatory legal act, changing regulatory policies and regulations of interdepartmental interaction;

- certification according to international standards.

Taking care of the environment is not only a regional task, but also a more global one, on which special attention, interest, and opportunities should be directed.

\section{Conclusions}

Only with the well-coordinated work of the person and the system will it be possible to act ahead of time, solve problems in advance, which is why it is so important to choose a special system for each of the regions [20,21].

The preservation and restoration of natural systems should be one of the priorities of the state and society.

In this work:

- the analysis of the current situation in the field of environmental hydro monitoring is carried out;

- the analysis of patents in the selected field is carried out;

- the main requirements for the created complex are defined;

- the functional structure of the system is developed;

- the functions of the complex are defined and described;

- the effect of the implementation of the developed system is determined.

The use of the complex will allow you to:

- comprehensively measure indicators;

- round the clock record indicators of the reservoir condition;

- collect statistics;

- generating reports for management;

- etc.

The high level of penetration of environmental links in various technical areas was confirmed, this will allow reflecting the presence of environmental problems through a hydro monitoring system not only in one region but also around the world as a whole [22]. This will contribute to more intensive observation and study of environmental problems in the most remote corners of the planet.

\section{References}

1. A. F. Poryadin and A.D. Khovansky.Assessment and regulation of the quality of the natural environment. Training manual for an environmental engineer M.: NUMC of the Ministry of Natural Resources of Russia, Publishing House "Priboy" (1996)

2. Federal project "Digital Ob-Irtysh basin"// URL: https://nticenter.spbstu.ru/nti_projects/43 (accessed: 1.04.2021)

3. Federal Institute of Industrial Property / / URL: https://www.fips.ru (accessed: 1.04.2021)

4. Method of integrated monitoring of the natural environment// URL: https://i.moscow/patents/RU2680652C2_20190225 (accessed: 1.04.2021)

5. Device for environmental monitoring and display of atmospheric air pollution // URL: https://istina.msu.ru/patents/99723329/ (accessed: 1.04.2021)

6. Information system for environmental monitoring and notification of local environmental pollution / / URL: https://i.moscow/patents/RU90238U1_20091227 (accessed: 1.04.2021) 
7. About the Ministry of Natural Resources and Ecology of the Russian Federation / / URL: https://www.mnr.gov.ru/about/ (accessed: 1.04.2021)

8. V. I. Izmalkov Ecological safety, methodology for predicting anthropogenic pollution and the basis for constructing chemical monitoring (St. Petersburg, 1994)

9. Methodological guidelines for assessing the degree of danger of soil contamination with chemicals (M., 1994)

10. Environmental protection and environmental management. Analytical control and monitoring. Water quality. Biological classification of rivers. Part 2: Guidelines for the presentation of data on the quality of watercourses based on biological indicators obtained in the study.: STB 17.13.05-25-2011/ISO 8689-2: 2000: Date of introduction 1.01.2012.

11. Standart 17.2.3.07-86. Rules for air control of localities.

12. Standart 17.1.3.07-82. Nature protection. Hydrosphere. Rules for monitoring the quality of water, reservoirs and watercourses.

13. Maistrenko, V. N. Ecological and analytical monitoring of superecotoxicants / V. N. Maistrenko, R. Z. Khamitov, G. K. Budnikov. (M.: Khimiya, 1996)

14. Standart 17.4.3.04-85. Nature protection. Soils. General requirements for control and protection from pollution. (M.: Publishing house of standards, 1986)

15. Golitsin A. N. Industrial ecology and monitoring of pollution of the natural environment. Textbook. (Moscow: Onyx Publishing House, 2011)

16. Afanasyev Yu. A., Fomin S. A. Monitoring and methods of environmental control. Textbook. (Moscow: MNEPU, 2008)

17. Izrael Yu. A. Ecology and control of the state of the natural environment. - L.: Gidrometeoizdat, 2008. - 560 p. - ISBN no.

18. Zaitsev V. A. Industrial ecology (Moscow: RKhTU, 2009)

19. Resolution of the Government of the Russian Federation of March 31, 2003 N 177 "On the organization and implementation of state environmental monitoring (State environmental monitoring)". Collection of Legislation of the Russian Federation. 14, 1278 (2003)

20. Brinchuk M. M. Environmental law: Textbook. - 2nd ed., reprint. and dop. (M.: Yurist, 2003)

21. Yurev, V., Shirokova, S., Iliashenko, O., Dybok, D. Proceedings of the 33rd International Business Information Management Association Conference, IBIMA 2019: Education Excellence and Innovation Management through Vision 2020, 9670-9676 (2019)

22. Volkova, V.N., Loginova, A.V., Shirokova, S.V., Kozlovskay, E.A. Proceedings of the 19th International Conference on Soft Computing and Measurements, SCM 2016, $497-$ 499, 7519825 (2016) 